\title{
Homelessness and health
}

\section{Jeffrey Turnbull MD MEd, Wendy Muckle RN MHA, Christina Masters BSc}

$\mathrm{H}$

omelessness is evolving into a national and international crisis. Within developed countries, homeless rates are now believed to approximate $\mathrm{I} \%$ of most urban populations. ${ }^{1}$ In the 200 I Canadian census, I4 I45 people were counted as living in a shelter. Of note, I490 (or I0\%) people were under the age of $15 .{ }^{2}$ This is made even more worrisome by the fact that these data likely underreport the true extent of homelessness because the census data represent the number of people living in a shelter on one day in May. This figure does not include the number of people staying in motels, transiently with friends, at a YMCA or a YWCA or on the street. This number also does not include people who may have recently become homeless and who were enumerated at their previous residence. Furthermore, these figures would have been drastically different if the census had been done in January when most shelters are at their capacity. In Ottawa in 2006, II63 children had to stay in an emergency family shelter, and in Australia, the 200 I census reported that I0\% of homeless people were children. ${ }^{1}$

In 2006, 9010 people in Ottawa spent time in a shelter for the homeless. ${ }^{3}$ This is an increase from 8664 people only 2 years before. ${ }^{3}$ In addition to this substantial increase, the face of homelessness has changed from single adult male alcoholics to adolescents, single mothers, underemployed people, elderly people and recent immigrants. ${ }^{3}$ Homeless people are the unstably housed and the addicted. They are also the vulnerable people in our communities who experience a health crisis or a family breakdown. Almost any life crisis can precipitate homelessness and shamefully, a large proportion of homeless people are children. Raising children in a shelter or on the streets predicts lifelong problems and places these children at high risk for homelessness as adults. ${ }^{4,5}$ In addition, young adolescents who find themselves on the street quickly become part of the street culture of violence, sexual exploitation and addiction. .,6 $^{4}$

On the surface, homelessness takes its origins from increased urbanization and gaps in the social safety net. The reality of what brings one to the streets and the circumstances that lead to chronic homelessness are infinitely more complex. Poverty, lack of social and family support, failed government policy, fetal alcohol syndrome, societal isolation, lack of resilience, psychiatric illness, and drug and alcohol addiction are all important variables that perpetuate homelessness and + are resistant to simple solutions. ${ }^{7}$ Living on the streets of a large urban centre is as much about being part of a culture or society with different norms and rules as it is about being without housing.

The cost of homelessness to society as a whole and to homeless people themselves goes well beyond the nuisance of public intoxication and pan handling and the impact on

\section{Key points of the article}

- The face of homelessness has changed from the adult male alcoholic to an increasingly diverse population with complex medical illnesses

- Despite substantially higher rates of illness, homeless people often lack effective health services

- Like any other complex social phenomena, the solutions will require complex, evidence-based integrated strategies that will require courage to implement

tourism. ${ }^{7}$ Despite our attempts to socially isolate homeless people, they are responsible for a disproportionate use of judicial, social and health care resources. ${ }^{9}$ At the same time, they do not materially benefit from this investment as they, for example, have similar health indices as those living in underdeveloped countries. Their age-adjusted mortality is 2- to 8 -fold greater than the housed population. ${ }^{10}$ Those living on the streets suffer from the same spectrum of medical illness as the housed population, yet the frequency of illness is substantially higher among homeless people. In addition, they may suffer from psychiatric disease, mental and physical disability and the consequences of drug and alcohol abuse, including violence, sexual exploitation and infectious diseases such as tuberculosis, HIV and hepatitis C. For example, the incidence of diseases such as diabetes and HIV in the chronically homeless population are substantially higher than in the housed population. ${ }^{10-12}$ A review of the literature shows that the incidence of HIV among Canadian youth living on the street is 6.I per I0o0, as compared with 0.20 per 1000 in the general population. ${ }^{12}$

Although actual measures of substance use among homeless people are hard to ascertain, it is estimated that the they are 6-7 times more likely than people in the general population to develop persistent and pervasive alcohol-related problems. ${ }^{13}$ However, it is important to note that the addiction profile among homeless people has shifted from the predominant use of alcohol to polysubstance use, which includes opiates, crack and crystal methamphetamines. ${ }^{12}$ The war on drugs has not curtailed the exploitation of people living in shelters.

Despite the public perception that the lives of people without homes are "responsibility free" and that these people choose not to have housing, homeless people report increased violence and drug availability, reduced meaningful social services and a correspondingly hostile community.

From Ottawa Inner City Health Inc. and the University of Ottawa, Ottawa, Ont. 
They are discouraged by a system that works for others but that works against them. For example, negotiating a complex health care system is almost impossible for many. Despite their heavy burden of illness, they lack access primary or preventive health services. ${ }^{5,7,10-12}$ In addition, transportation to and from medical appointments is often impossible because of timing and expense. Health cards, prescriptions and integrated health services are not usually within their grasp, although health and social policy dictates that they are entitled to these benefits. As a consequence, often the only health care homeless people receive is through the emergency department, which is costly and ineffective., ${ }^{9,11}$ These problems are not unique to health care: they apply equally to the housing, judicial and social systems.

Despite the many challenges, there is hope. There is now an emerging body of evidence identifying cost-effective approaches to address many of the root causes of homelessness and the associated health and social consequences. ${ }^{5,10}$ These strategies include affordable and supportive housing, enhanced social inclusion, harm-reduction strategies, individual and community empowerment, community mental health services and poverty-reduction strategies. ${ }^{14}$

Unfortunately, effective strategies run counter to the ideologies, beliefs and expectations of citizen groups and political parties. In addition, our elected representatives often seek politically expedient, simple and short-term solutions to complex social and health problems. The controversy surrounding strategies like social housing and harm reduction are filled with emotion and strong positions. However, like all complex social issues, they are seldom explained in a short sound bite or within the mandate of a political party despite their best intentions. Successful models such as "housing first" require a long-term integrated strategy that is not solely driven by short-term cost savings.

In order to stem this crisis, first we must identify eradication of homelessness as a major social problem that deserves meaningful government funding. Community engagement and leadership are key to making this metastatic social cancer a front-and-centre priority. Second, every effort should be made to "depoliticize" the problem of homelessness. This may be achieved by focused dialogue involving stakeholders from different backgrounds, ideologies and political colours. Third, strategic investments and energy should largely be fo- cused on evidence-based programs, so that we invest in programs that work rather than in ideologic solutions. We do not believe in a radical departure from the past, but rather in enhanced leadership, collaboration and targeted evidence-based investments. There is no shortage of great ideas, and effective solutions are well within our reach.

This article has been peer reviewed.

Competing interests: None declared for Wendy Muckle and Christina Masters. Jeffery Turnbull has received honoraria from Ottawa Inner City Health Inc.

Contributors: All of the authors contributed to the conception and design of the manuscript, drafted the article and revised it critically for important intellectual content. All of the authors approved the final version for publication.

\section{REFERENCES}

I. Rebeccas Community. Homeless Statistics. Australia: The Community. Available: www.homeless.org.au/statistics/ (accessed 2007 Sept 25).

2. Statistics Canada. 200I Census analysis series: collective dwellings. Ottawa: Statistics Canada: 2002. Available: wwwi2.statcan.ca/english/censusor/Products /Analytic/companion/coll/pdf/96Foo30XIE200I004.pdf (accessed 2007 Sept 26).

3. Alliance to End Homelessness. Experiencing homelessness: third report card on ending homelessness in Ottawa. Ottawa: The Alliance; 2006. Available: www .endhomelessnessottawa.ca/documents/ReportCardonEndingHomelessnessin OttawaJan-Dec2006webemail.pdf (accessed 2007 Aug 20).

4. Haley N, Roy E, Leclerc P, et al. HIV risk profile of male street youth involved in survival sex. Sex Transm Infect 2004;80:526-30.

5. Kidd SA, Davidson L. Youth homelessness: a call for partnerships between research and policy. Can J Public Health 2006;97:445-7.

6. Roy E, Boudreau JF, Leclerc P, et al. Trends in injection drug use behaviors over Io years among street youth. Drug Alcohol Depend 2007;89:170-5.

7. Lee BA, Price-Spratlen T, Kanan JW. Determinants of homelessness in metropolitan areas. Journal of Urban Affairs 2003;25:335-56.

8. Dunford JV, Castillo EM, Chan TC, et al. Impact of the San Diego Serial Inebriate Program on use of emergency medical resources. Ann Emerg Med 2006;47:328-36.

9. Nosyk B, Li X, Sun H, et al. The effect of homelessness on hospitalization of patients with HIV/AIDS. AIDS Care 2007;19:546-53.

Io. Hwang SW. Mortality among men using homeless shelters in Toronto, Ontario. JAMA 2000;283:2152-7.

II. Schanzer B, Dominques B, Shrout P, et al. Homelessness, health status and health care use. Am J Public Health 2007;97:464-9.

I2. Boivin JF, Roy E, Haley N, et al. The health of street youth: a Canadian perspective. Can J Public Health 2005;96:432-7.

I3. Fischer PJ, Breakey WR. The epidemiology of alcohol, drug and mental disorders among homeless persons. Am Psychol 200I;46:1115-28.

I4. Padget DK, Gulcur L, Tsemberis S. Housing First services for people who are homeless with co-occurring serious mental illness and substance abuse. Res Soc Work Pract 2006;16:74-83.

Correspondence to: Dr. Jeffrey Turnbull, Ottawa Inner City Health Inc., Unit G, 500 Old St. Patrick St., Ottawa ON KIN gG4; fax613562 4505; turnbull@ottawahospital.on.ca 